\title{
Impedimetric Humidity Sensor Based on Nanohybrid Composite of Conducting Poly(diphenylamine sulfonic acid)
}

\author{
Şule Dinç Zor and Hüsnü Cankurtaran \\ Department of Chemistry, Yildiz Technical University, Davutpasa, 34220 Istanbul, Turkey \\ Correspondence should be addressed to Şule Dinç_Zor; sule_dinc@yahoo.com
}

Received 22 December 2015; Accepted 10 February 2016

Academic Editor: Sang Sub Kim

Copyright (C) 2016 Ş. Dinç Zor and H. Cankurtaran. This is an open access article distributed under the Creative Commons Attribution License, which permits unrestricted use, distribution, and reproduction in any medium, provided the original work is properly cited.

\begin{abstract}
Interdigitated thin film humidity sensors have been prepared using organic/inorganic nanocomposites of poly(diphenylamine sulfonic acid) (PSDA), 3-mercaptopropyltrimethoxysilane (MPTMS), and nano-ZnO. Humidity sensing properties of the sensors, regarding the effect of nano- $\mathrm{ZnO}$ addition and the applied alternating current frequency, were studied by impedance measurements in the frequency range of $100 \mathrm{~Hz}-1 \mathrm{kHz}$. It was found that the sensing properties of the $\mathrm{ZnO}$ based nanocomposite sensors had better properties than those of the PSDA-MPTMS based composite due to contribution of the nanomaterial. Good sensitivity (about three orders' magnitude change in impedance), linear response, rapid response (90 s) and recovery (60 s), and low hysteresis within $4 \%$ as well as good repeatability and stability in the range from $12 \%$ to $95 \% \mathrm{RH}$ were obtained.
\end{abstract}

\section{Introduction}

The development of humidity sensors has showed a remarkable progress because of using various types of sensing materials in recent years. The sensing materials used in humidity sensors can be classified into ceramics [1-3], polymers [4, 5], and composites [6-8]. Ceramic humidity sensors based on semiconductor metal oxides have some critical limitations such as elevated working temperature, insufficient sensitivity, and repeatability. Polymeric humidity sensors have been widely studied for ten years. Almost all of the humidity sensors based on polymers sensitively operate at room temperature. In terms of the stability of the sensors, some highly hydrophilic polyelectrolyte and functional polymer based sensors are not sufficiently resistant at high humidity conditions. However, their hydrophilicity and ionic conductivity can be easily adjusted using various methods such as copolymerization, cross-linking with relatively hydrophobic and insulating polymers. Composites in humidity sensors consist of polymer and another material which is insulating or conducting polymer [9], metal [10, 11], metal oxide [12, $13]$, or nanomaterials $[14,15]$. So, these composite humidity sensors, which combine with unique property and synergistic effect of each component, have some advantages such as high sensitivity, small hysteresis, quick response, and high stability.

Nanoscaled materials have high adsorption capacity due to their small grain size and large specific surface area. Many kinds of nanometal oxides such as, $\mathrm{TiO}_{2}[16,17], \mathrm{SnO}_{2}[18,19]$, $\mathrm{SiO}_{2}$ [20], $\mathrm{ZrO}_{2}$ [21], and $\mathrm{ZnO}$ [22-27] have been widely employed alone or along with other polymers in humidity sensors due to these properties. Among them, $\mathrm{ZnO}$ is one of the most well-known gas sensing materials, which has been extensively carried out for study of some gases and vapors such as ethanol [28-30], acetone [31], ammonia [32], $\mathrm{NO}_{2}$ [33], $\mathrm{CO}$ [34], $\mathrm{H}_{2} \mathrm{~S}$ [35], and hydrogen [36].

Conducting polymers which are able to change in electrical conductivity with relative humidity are good candidates for humidity sensing material. They also have high sensitivity at room temperature, ease of synthesis, facile processability, and high stability [37]. Moreover, the combination of conducting polymers with inorganic nanoparticles leads to a development on humidity sensors with superior properties. Many reports have been published about humidity sensor applications based on nanomaterial/conducting polymer composites $[21,38-40]$. In our previous study, we reported that the water soluble/conductive 
poly(diphenylamine sulfonic acid) in its diblock copolymer and blend with poly(ethylene glycol) and poly(vinyl acetateco-butyl acrylate) would be a good candidate as humidity sensing material [41]. However, water-soluble properties of such composites may require the fixing of the watersoluble component into a durable matrix for measurements in highly humid or condensed water atmosphere. In this study, we aimed to enhance the stability and sensitivity of the PSDA based humidity sensors. For this purpose, 3mercaptopropyltrimethoxysilane (MPTMS) and nano $\mathrm{ZnO}$ powder were chosen for matrix modification to construct the interdigitated impedimetric type humidity sensors.

It is known that reactive silanes are very efficient to improve adhesion properties at the interfaces, water durability, and long-term stability at high temperature and humidity [42]. Among the reactive silanes, mercapto silanes can be selfassembled onto the metal surfaces such as gold and silver and the adhesion properties of coatings can be further improved [43]. In this study, the silver based interdigitated electrodes were used. Our studies on gold based electrodes by mass sensitive quartz crystal microbalance method have been also currently conducted. Therefore, it was expected that MPTMS may be a good candidate to adjust the hydrophilicity and to enhance the stability and water durability of the PSDA based humidity sensors. Nano- $\mathrm{ZnO}$ was chosen due to its small grain size and high surface area for high humidity sensitivity. There is no report about impedimetric humidity sensor based on organic/inorganic nanocomposite of the conducting poly(diphenylamine sulfonic acid) in literature. The electrical properties of the composite and nanocomposite were measured by impedance measurements at various relative humidity in the frequency range of $100 \mathrm{~Hz}-1 \mathrm{kHz}$ at constant temperature.

\section{Experimental Procedure}

2.1. Materials. $\mathrm{ZnO}$ nanoparticles (grain size $<100 \mathrm{~nm}$ ) were supplied from ABCR. Sodium salts of diphenylamine sulfonic acid and hydrochloric acid were analytical grade Aldrich products. The electrochemical polymerization of diphenyl amine sulfonic acid (PSDA) was carried out by a method described previously [41]. 3-Mercaptopropyltrimethoxysilane (MPTMS, purity 95\%, ABCR) was used without further purification.

2.2. Instruments and Analysis. Vibrational spectra of the nanocomposite materials were obtained using a Perkin Elmer Spectrum One FT-IR spectrometer. Scanning electron microscope (SEM) images of prepared sensor films on precleaned microscope slides were characterized by a Philips XL 30ESEM-FEG/EDAX instrument. Electrical characteristics of the nanocomposites as a function of relative humidity $(\mathrm{RH})$ were measured with LCR meter (HIOKI 3522-50) in a test chamber at constant temperature $\left(20 \pm 1^{\circ} \mathrm{C}\right)$ and $0.2 \mathrm{~V}$ from $1 \mathrm{kHz}$ to $100 \mathrm{~Hz}$. All the measurements were carried out at different relative humidity levels in the range of $10-95 \% \mathrm{RH}$. The RH levels were generated by saturated salt solution method and controlled by a Carl Roth P330 capacitive type of commercial humidity sensor. This humidity sensor has a
$0-99 \%$ relative humidity measuring range with an accuracy of $\pm 3 \%$ RH.

2.3. Preparation of Humidity Sensors Based on Nanocomposite. $80 \mu \mathrm{L}$ of $10 \mathrm{wt} . \%$ PSDA in $0.1 \mathrm{M} \mathrm{HCl}$ solution and $2 \mu \mathrm{L}$ of pure MPTMS were mixed. The mixture was stirred and dispersed by ultrasonic method. After ultrasonication, $5 \mu \mathrm{L}$ of sol-gel solution was carefully dropped onto the epoxy based substrate with a circular silver coated copper interdigitated electrode (thickness of the digits was $20 \mu \mathrm{m}$ ). The prepared films were allowed to dry at room temperature. Finally, the as-coated electrode was heated at $105^{\circ} \mathrm{C}$ for 2 hours in an oven to fabricate humidity sensor based on conducting polymer as shown in Figure 1.

To prepare humidity sensors based on nanocomposite, nanometer $\mathrm{ZnO}$ particles were added to sol-gel solution which was described above. The mixture was sonicated to achieve a uniform dispersion of nanoparticles. Different PSDA-MPTMS nanocomposites were prepared and the same casting, drying, and curing procedures mentioned above were used to obtain nanocomposite films. Nanocomposites were prepared by taking into consideration the weight percentage of nanoparticle used in the sensors. The composition of the prepared sensors is shown in Table 1. The upper edges of the silver digits were completely covered by the films after curing and the film thicknesses were estimated to be ca. 25$30 \mu \mathrm{m}$ from SEM images.

\section{Results and Discussion}

3.1. FTIR Spectroscopy Results. Figure 2 shows the FTIR spectra of the PSDA-MPTMS (S1), nanometer $\mathrm{ZnO}$, and PSDA-MPTMS-ZnO (S4) nanocomposite. All characteristic peaks of PSDA [44] appear in the FTIR spectrum of PSDAMPTMS composite. The broad band at around $2500 \mathrm{~cm}^{-1}$ which is assigned to the -SH group of MPTMS disappeared in the $\mathrm{ZnO}$ based nanocomposite [45]. Further, the magnitude of the distinct stretching vibration band of $\mathrm{ZnO}$ near $480 \mathrm{~cm}^{-1}$ decreases in PSDA-MPTMS-ZnO nanocomposite. These results indicate the interaction of the -SH group with $\mathrm{ZnO}$ [46-48]. We must note here that the interactions among weak acidic thiol groups on polysilane, hydrolyzed silanols, and deprotonated basic amine groups on PSDA should also be taken into account $[49,50]$. The broad band around $3400 \mathrm{~cm}^{-1}$ in each spectrum corresponds to $\mathrm{O}-\mathrm{H}$ stretching of silanol groups and adsorbed water.

3.2. Microstructure Characteristics of PSDA-MPTMS and PSDA-MPTMS-ZnO Nanocomposite Thin Films. The SEM images of the PSDA-MPTMS (S1) and PSDA-MPTMS-ZnO (S4) nanocomposite are shown in Figures 3(a) and 3(b), respectively. As shown from the SEM images of PSDAMPTMS film in Figure 3(a), PSDA is uniformly dispersed, like microdroplets, in the highly ordered polysilane network. It is shown from Figure 3(b) that $\mathrm{ZnO}$ nanoparticles were almost homogeneously distributed in the matrix. Although some cracks were observed in the $\mathrm{ZnO}$ based composite film, there was not any obstacle such as physical disintegration of the films in the whole sensors for the measurements at dry 


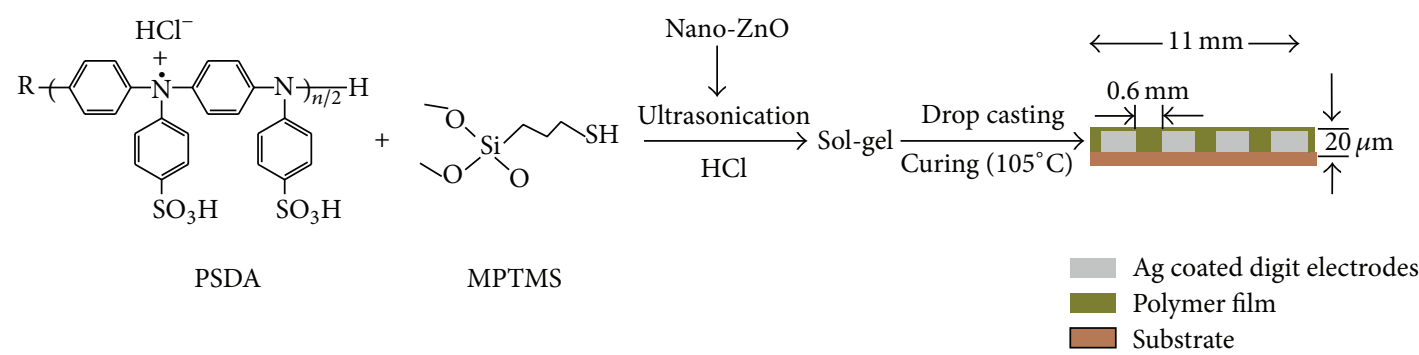

(a)

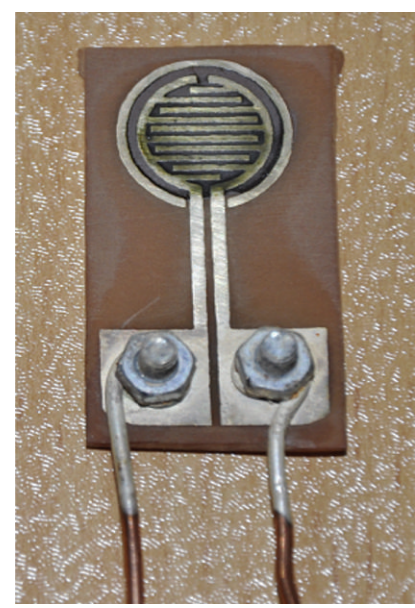

(b)

FIgURE 1: Preparation procedure and a schematic side view (a) and photo image (b) of the polymer coated interdigitated electrode.

TABLE 1: Composition of the humidity sensors based on nanocomposite before curing.

\begin{tabular}{lccc}
\hline Prepared sensor & $10 \mathrm{wt} \%$ PSDA $(\mu \mathrm{L})$ & MPTMS (pure, $\mu \mathrm{L})$ & ZnO $(\mathrm{wt} . \%)$ \\
\hline S1 & 80 & 2 & - \\
S2 & 80 & 2 & 10 \\
S3 & 80 & 2 & 30 \\
S4 & 80 & 2 & 50 \\
\hline
\end{tabular}

and humid atmosphere. It seems that a more stable structure in terms of durability under high humidity conditions is provided by adding MPTMS into the composite [46].

\subsection{Humidity Sensing Behaviors of PSDA-MPTMS and PSDA-MPTMS ZnO Nanocomposites}

3.3.1. Complex Impedance Characteristics. Impedance spectroscopy is a powerful technique to understand the conduction mechanisms of humidity sensors [51]. Complex impedance spectrum is measured by applying a single voltage to the interface and measuring the phase shift and amplitude of the electrical parameters for the frequency $(f)$ range explored. The change in total impedance can be represented as a Nyquist plot, in which the imaginary part of the material's impedance, $Z_{\mathrm{im}}$, or its reactance, is plotted against the real part of the impedance, $Z_{\text {re }}$, or resistance for each excitation frequency. Another representation of the frequency variation of impedance can be found through Bode plots. In Bodediagrams, the absolute value of the total impedance or the imaginary part of the impedance and the phase angle are plotted as a function of the angular frequency $(w=2 \pi f)$, in a logarithmic and semilogarithmic plot, respectively. This yields information about the electrode structure. Planar electrodes will result in plots where the linear part of the curve has a slope of -1 , while the slope will be $-1 / 2$ for a porous electrode. Extrapolation of this line to $\log w=0$ gives $\log \left(1 / C_{D}\right)$, where $C_{D}$ is the double layer capacitance.

The complex impedance spectra of PSDA-MPTMS (S1) and PSDA-MPTMS-ZnO (S4) nanocomposites at low $(\sim 10 \% \mathrm{RH})$ and moderate humidity $(\sim 60 \% \mathrm{RH})$ are shown in Figures 4(a) and 4(b), respectively, in a form of Nyquist plot. As can be seen from the figures, PSDA-MPTMS and PSDAMPTMS-ZnO sensors have similar impedance behavior at low humidity levels in the frequency range studied. At moderate humidity levels, they gave semicircles, indicating the decrease in their capacitive reactance and resistance values. With further increasing of humidity, the semicircle radius reduced gradually and a straight line appeared at lower frequencies and high humidified conditions (data not 


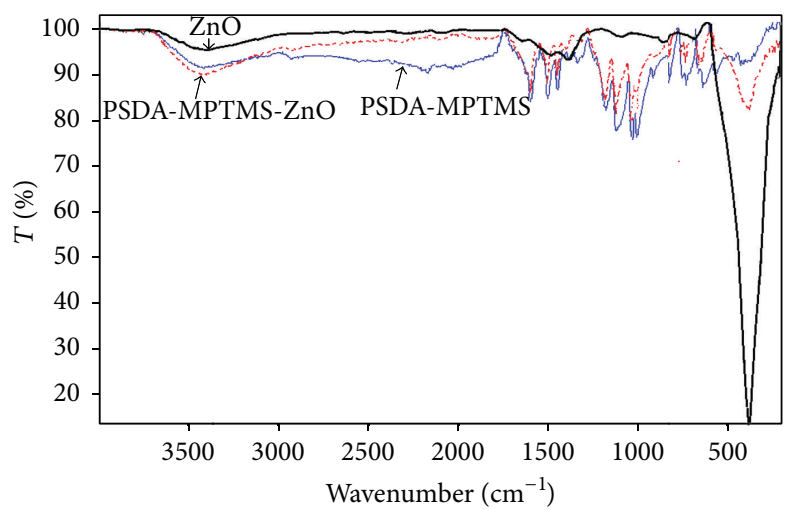

FIGURE 2: FTIR spectra of nanometer ZnO (black line), PSDA-MPTMS (blue line), and PSDA-MPTMS-ZnO nanocomposite (red line) films.

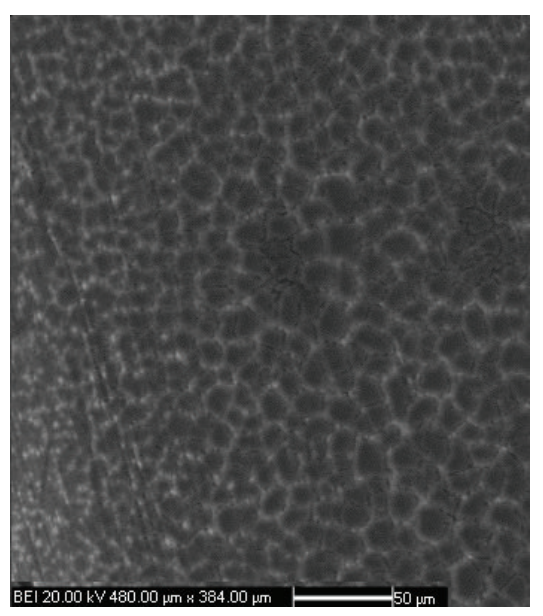

(a)

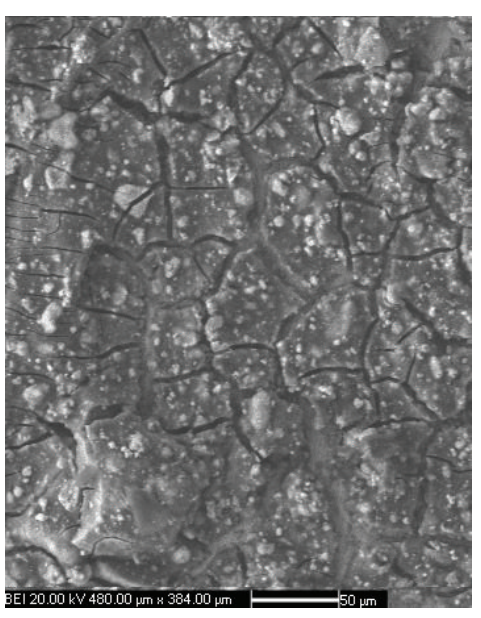

(b)

FIGURE 3: SEM images of (a) PSDA-MPTMS and (b) PSDA-MPTMS-ZnO nanocomposite.

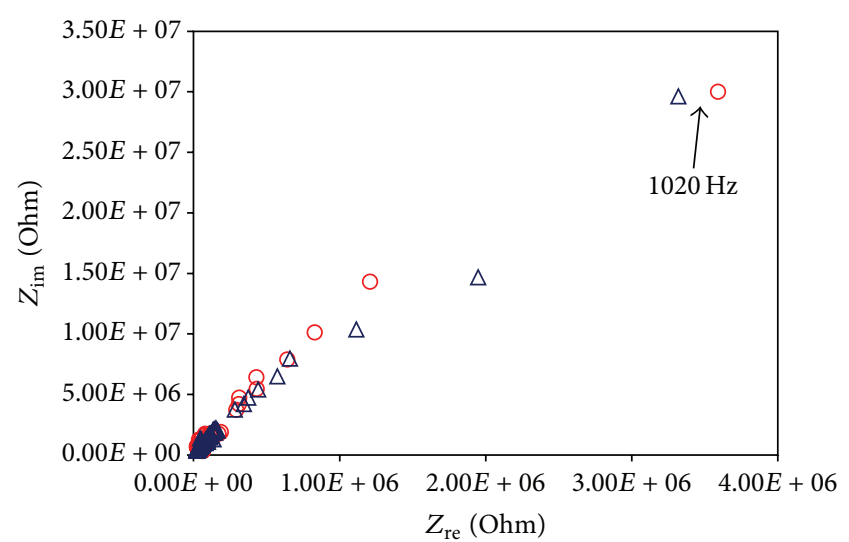

O S1 10\% RH

$\triangle \mathrm{S} 412 \% \mathrm{RH}$

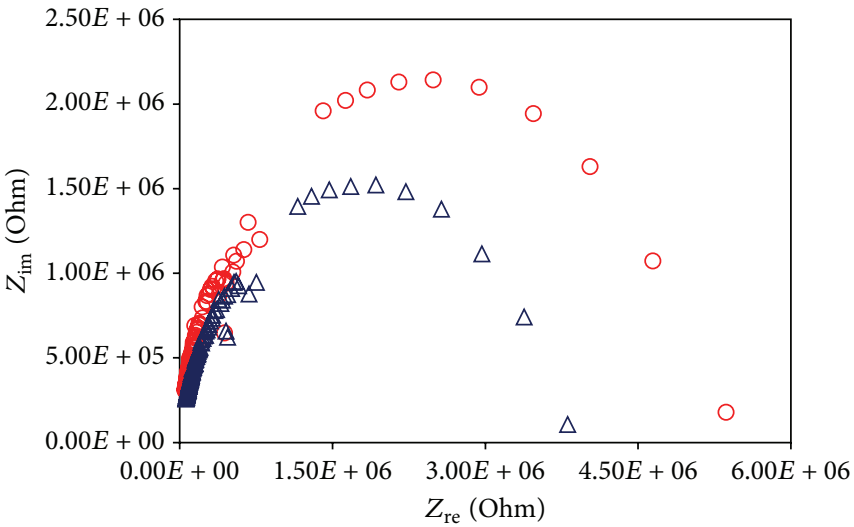

O $\mathrm{S} 156 \% \mathrm{RH}$

$\triangle \mathrm{S} 458 \% \mathrm{RH}$

(a)

(b)

FIgURe 4: Nyquist plots of S1 and S4 humidity sensors at $20^{\circ} \mathrm{C}$ and different humidity conditions: (a) low RH, (b) moderate RH. 


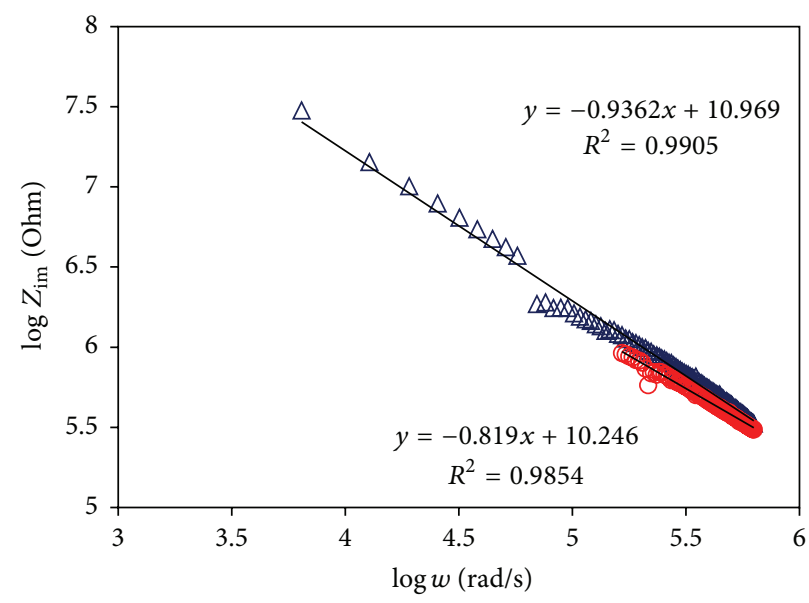

$\triangle \mathrm{S} 110 \% \mathrm{RH}$

O $\mathrm{S} 158 \% \mathrm{RH}$

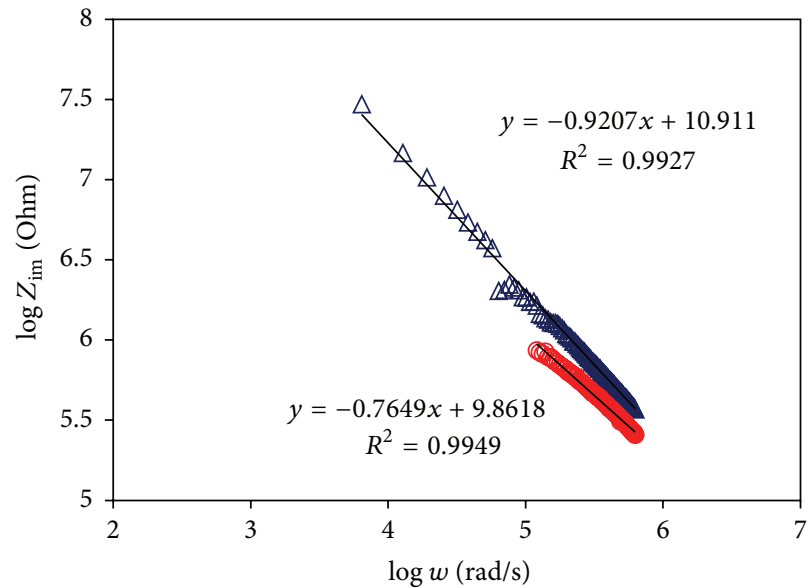

$\triangle \mathrm{S} 412 \% \mathrm{RH}$

O $\mathrm{S} 460 \% \mathrm{RH}$

(a)

(b)

Figure 5: Bode plots of (a) S1 and (b) S4 at low and moderate humidity conditions.

shown). It can be obviously shown in the Figure 4 that PSDA-MPTMS-ZnO sensor has lower impedance, that is, lower resistance and capacitive reactance than that of PSDAMPTMS sensor at moderate humidity levels. Furthermore, it can be seen from the plots that the imaginary part of the impedance, rather than the resistance, is more affected in the presence of water. PSDA-MPTMS-ZnO sensor seemed to have a higher absorption capability of water molecules. It can also be claimed from the slopes of Bode plots in Figures 5(a) and 5(b) that PSDA-MPTMS and PSDA-MPTMS-ZnO sensors behave as planar electrodes, and they have similar capacitances at low humidity conditions. However, PSDAMPTMS-ZnO sensor has a lower slope than that of PSDAMPTMS sensor and exhibits a more porous electrode structure and a higher capacitance at moderate humidity levels. It is known that cracks create porosity on the surfaces [50]. Higher porosity and nanosized $\mathrm{ZnO}$ grains increases surface to volume ratio of the materials and enhances diffusion ability of water into or out of the porous structure. It can be concluded that both the capacitive and ionic charge transfer processes contribute to the sensor's response but the capacitive reactance mainly determines the total impedance changes. With an increase of humidity through saturation, the semicircles almost disappeared and the similar straight lines were obtained at low frequency levels for both of them. This might be due to the contribution of ionic species in the composites.

\subsubsection{The Effect of $\mathrm{ZnO}$ on Humidity-Impedance Character-} istics. The effects of the nanometer $\mathrm{ZnO}$ content on the impedance responses and humidity sensing of the PSDAMPTMS-ZnO nanocomposite thin films were measured at various $\mathrm{RH}$, and the results are shown in Figure 6. PSDAMPTMS based sensor was also studied for comparison.

As can be seen from Figure 6, the impedance of PSDAMPTMS decreased exponentially from $4.2 \times 10^{4} \mathrm{k} \Omega$ to 1.9

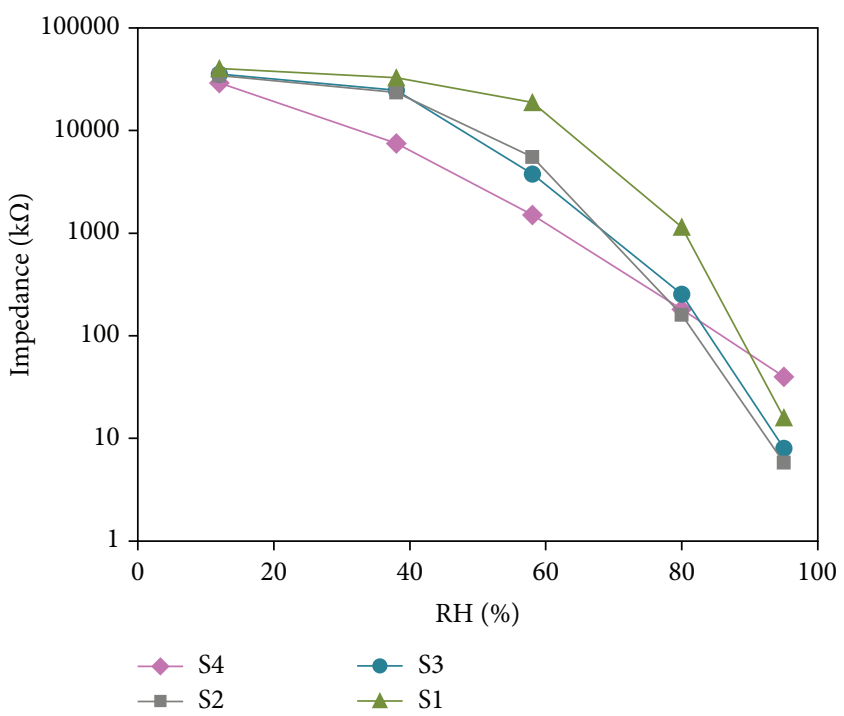

FIGURE 6: Impedance values versus RH for S1 and nanocomposites; $\mathrm{S} 2, \mathrm{~S} 3$, and $\mathrm{S} 4$ measured at $0.2 \mathrm{~V}, 1 \mathrm{kHz}$.

$\times 10^{1} \mathrm{k} \Omega$ for humidity change from 10 to $91 \% \mathrm{RH}$. It can be calculated that the impedance changed approximately by more than three orders of magnitude over the measured $\mathrm{RH}$ range. It was not sensitive to low humidity $(10-50 \% \mathrm{RH})$, while the further increase of RH results in sharp decrease in impedance. The adding of MPTMS was expected to lead to increasing stability of the sensors in high RH levels. It must be noted here that MPTMS did not have any significant response towards humidity in the preliminary studies.

Similar to PSDA-MPTMS sensor, as shown from Figure 6, the impedance of the all $\mathrm{ZnO}$ based sensors changed by more than three orders of magnitude over the same $\mathrm{RH}$ range. Among them, PSDA-MPTMS-ZnO (S4) showed the best linearity with a correlation coefficient of 0.9832 in the 


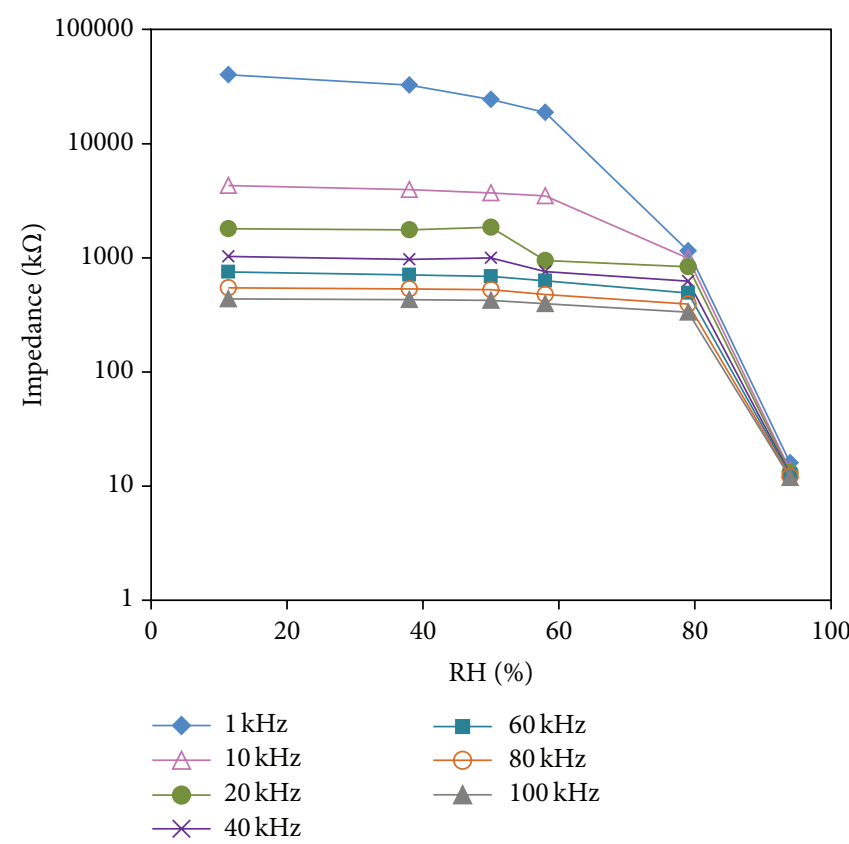

(a)

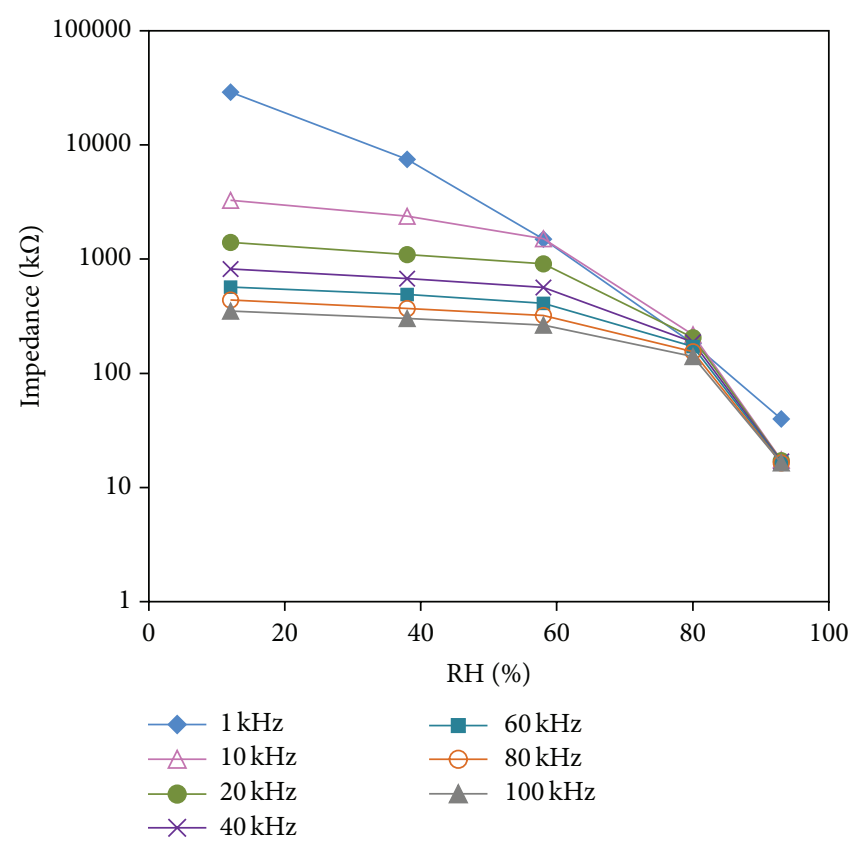

(b)

FIGURE 7: Impedance values versus RH for (a) S1, (b) S4 at various frequencies and $0.2 \mathrm{~V}$.

range of $12 \%$ to $95 \% \mathrm{RH}$. Therefore, $\mathrm{S} 4$ nanocomposite was selected for further research. It was concluded that all of humidity sensors are sensitive to water molecules. This is considered due to the hydrophilic groups on $\mathrm{ZnO}$ surface and ionic groups and doped ions in PSDA to interact with water molecules. Consequently, the impedance of the sensors decreased with the increasing absorption of water molecules. As mentioned in Section 3.3.1, the high surfaceto-volume ratio and porous structure of PSDA-MPTMS$\mathrm{ZnO}$ sensors allow for more water absorption at moderate humidity ranges. One thing to note here from Figure 6 is that the S4 sensor has a higher impedance than the others at highest humidity $(95 \% \mathrm{RH})$, while it has a significantly lower impedance at moderate humidity levels. This behavior confirms the increasing surface area and porosity of the films but the decreasing the quantity of the ionic carriers with the increase of $\mathrm{ZnO}$ content. Since water has very high dielectric constant at room temperature, the effective dielectric constant and the capacitance of the film will increase accordingly. At low and moderate humidity, the coverage of water on the surface did not seem to be continuous; the electrolytic conduction is difficult. At high humidity, several water layers are formed, which accelerate the transfer of $\mathrm{H}^{+}$or $\mathrm{H}_{3} \mathrm{O}^{+}$. In this condition, ions in PSDA also dissolve in the adsorbed water. As a result, ionic charge transfer process appeared at high humidity.

3.3.3. The Effect of Frequency on Response. The dependence of impedance response on the applied frequency was measured as shown in Figures 7(a) and 7(b) for PSDA-MPTMS (S1) and PSDA-MPTMS-ZnO (S4) based sensors, respectively. The effect of frequency on the impedance is greater at low and moderate RHs compared to the state at high RH. The impedance decreases when the frequency increases. Polarization of the water molecules is higher in the case of low frequencies. This leads to higher electrostatic attractive forces between water molecules and sensitive layer at low alternating current frequencies and consequently higher impedance changes than those of higher frequencies [41]. S1 and S4 display almost identical behaviors towards applied frequencies. The linearity of the responses is getting better toward lower alternating current frequencies and the best one was obtained for S4 based sensor at $1 \mathrm{kHz}$. Applied frequency and voltage were thus kept constant at $1 \mathrm{kHz}$ and $0.2 \mathrm{~V}$, respectively.

3.3.4. Repeatability, Hysteresis, and Long-Term Stability. Figure 8 illustrates a typical time dependent response of PSDA-MPTMS-ZnO (S4) sensor measured by exposing it to cycle of $10 \% \mathrm{RH}$ and $95 \% \mathrm{RH}$ to investigate sensor repeatability. The relative standard deviations in impedance values at low and high humidity levels in this experiment were less than $1 \%$. It can be inferred that the humidity sensing process is extremely reversible and repeatable for the nanocomposite sensor. Furthermore, for one month at least, sensor responses do not have significant deviation by measuring the impedance change at various \% RH over this period even in the highest RH. The measurements were repeated for S4 sensor every 7 days for 1 month. The impedance variation is less than $4 \% \mathrm{RH}$ at each humidity region. This shows the long-term stability of the PSDA-MPTMS-ZnO (S4) sensor at various humidity. Also, hysteresis was studied to determine the repeatability of the nanocomposite sensor. As shown in Figure 9, the response behavior of the sensor did not 


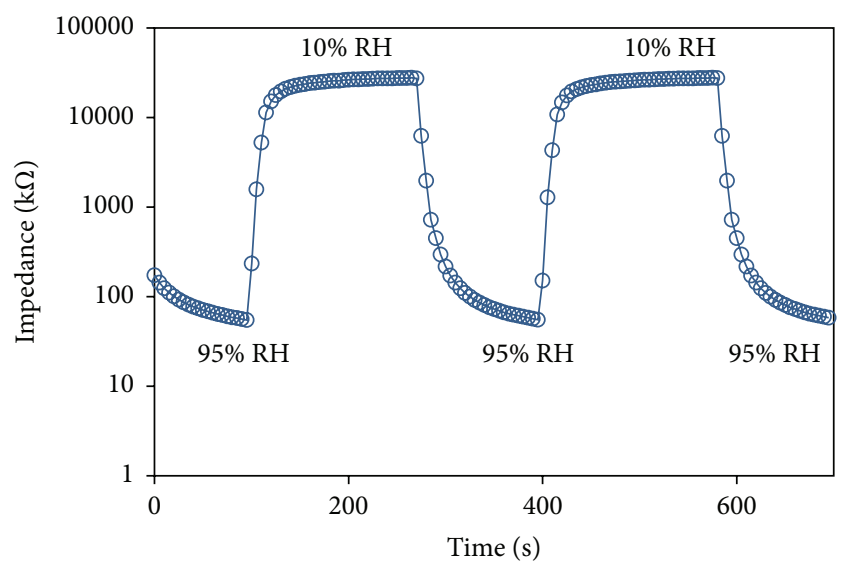

FIGURE 8: Repetitive response of S4 at 10 and $95 \% \mathrm{RH}$, measured at $0.2 \mathrm{~V}, 1 \mathrm{kHz}$

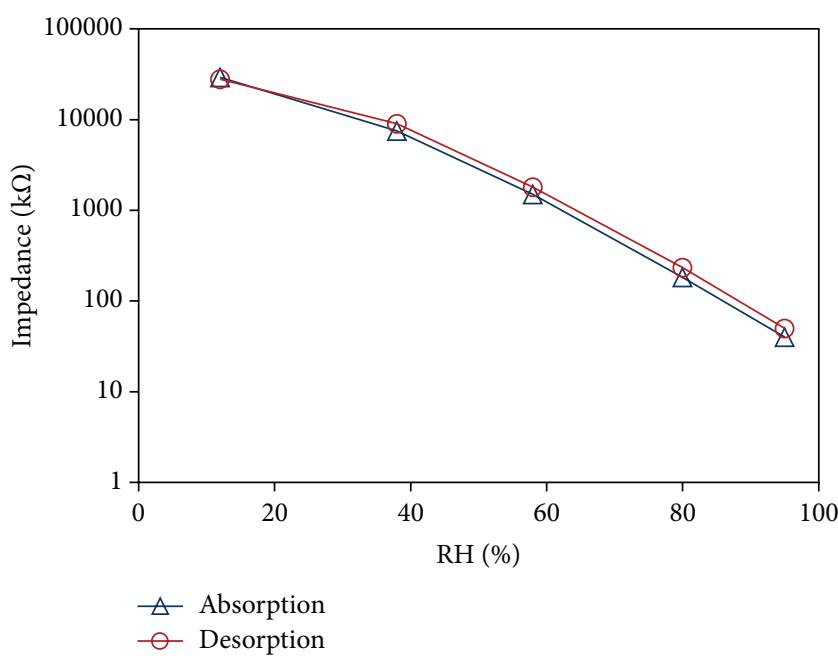

Figure 9: Hysteresis of the S4 at 12 and $95 \% \mathrm{RH}$, measured at $0.2 \mathrm{~V}$, $1 \mathrm{kHz}$.

change during the humidity measurements from low to high $\mathrm{RHs}$, and then in the reverse direction between $12 \% \mathrm{RH}$ and $95 \% \mathrm{RH}$. It can be regarded that the nanocomposite sensor exhibits a low hysteresis $(<4 \% \mathrm{RH})$ in the whole humidity range. Compared with the nanocomposite sensor, PSDAMPTMS sensor shows relatively high hysteresis at moderate humidity levels (the maximum hysteresis was $10 \% \mathrm{RH}$ at $60 \% \mathrm{RH})$.

3.3.5. Response and Recovery Time. It is well known that response and recovery behavior are an important characteristic for evaluating the performance of the sensing materials. The response and recovery times of the humidity sensors have been measured by adjusting the humidity between low and high levels. The response or recovery time is the time required to achieve $90 \%$ of the steady response when the humidity is increased or decreased between two levels, respectively [52]. The response (adsorption) and recovery (desorption) times of the sensors were measured by suddenly changing

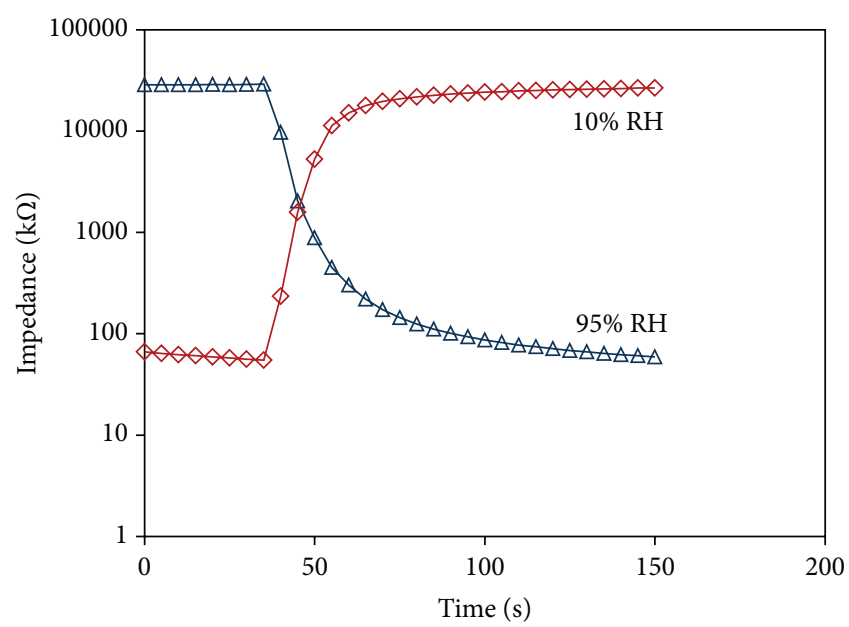

$\triangle$ Absorption
$\diamond$ Desorption

FIGURE 10: Response-recovery time of S4 measured at $0.2 \mathrm{~V}$ and $1 \mathrm{kHz}$.

humidity from $10 \%$ to $95 \% \mathrm{RH}$ and from $95 \%$ to $10 \% \mathrm{RH}$, respectively. Figure 10 represents the response and recovery behavior of PSDA-MPTMS-ZnO (S4) sensor. The response time of the adsorption process is $90 \mathrm{~s}$, and the recovery time of the desorption process is $60 \mathrm{~s}$. Also S1, S2, and S3 sensors have shown good response and recovery times, but, in comparison with S4, they have a narrow linear humidity range (as shown in Figure 6) and/or high hysteresis (data not shown).

The above experimental results indicated that the $\mathrm{ZnO}$ nanocomposite of PSDA-MPTMS showed satisfying humidity sensing properties such as a good repeatability, low hysteresis and high sensitivity in a wide humidity range.

\section{Conclusion}

In the present work, humidity sensitive PSDA-MPTMS and PSDA-MPTMS-ZnO nanocomposite were prepared by a simple mechanical mixing method and their humidity sensing characteristics were investigated. The PSDA-MPTMS$\mathrm{ZnO}$ nanocomposite humidity sensor showed the best linearity over a wide humidity range in comparison with the sensor composed of PSDA-MPTMS alone. Due to water soluble nature of the PSDA, MPTMS was added into the composites to adjust the hydrophilicity and the stability of the sensing layer and availed itself. Addition of $\mathrm{ZnO}$ into the composite enhanced the sensitivity of the sensors at low and moderate humidity levels. The nanocomposite with $50 \mathrm{wt} . \%$ of $\mathrm{ZnO}$ sensor displays good sensitivity, linear response, rapid response (90 s) and recovery (60 s), and low hysteresis within $4 \%$ as well as good repeatability in $12-95 \%$ RH. Compared with the similar humidity sensors in literature, the thin film sensors of PSDA have similar or better properties [22-27, $41,50]$. Consequently, PSDA-MPTMS-ZnO nanocomposite could be a promising candidate for humidity sensing in practical applications. 


\section{Conflict of Interests}

The authors declare that there is no conflict of interests regarding the publication of this paper.

\section{Acknowledgment}

This research was supported by Yildiz Technical University Scientific Research Projects Coordination Department (Project no. 2011-01-02-DOP05).

\section{References}

[1] N. Yamazoe and Y. Shimizu, "Humidity sensors: principles and applications," Sensors and Actuators, vol. 10, no. 3-4, pp. 379398, 1986.

[2] T. Seiyama, N. Yamazoe, and H. Arai, "Ceramic humidity sensors," Sensors and Actuators, vol. 4, pp. 85-96, 1983.

[3] E. Traversa, "Ceramic sensors for humidity detection: the stateof-the-art and future developments," Sensors and Actuators: $B$ Chemical, vol. 23, no. 2-3, pp. 135-156, 1995.

[4] Y. Sakai, Y. Sadaoka, and M. Matsuguchi, "Humidity sensors based on polymer thin films," Sensors and Actuators B: Chemical, vol. 35, no. 1-3, pp. 85-90, 1996.

[5] B. Adhikari and S. Majumdar, "Polymers in sensor applications," Progress in Polymer Science, vol. 29, no. 7, pp. 699-766, 2004.

[6] A. C. Power, A. J. Betts, and J. F. Cassidy, "Silver nanoparticle polymer composite based humidity sensor," Analyst, vol. 135, no. 7, pp. 1645-1652, 2010.

[7] S. Jain, S. Chakane, A. B. Samui, V. N. Krishnamurthy, and S. V. Bhoraskar, "Humidity sensing with weak acid-doped polyaniline and its composites," Sensors and Actuators B: Chemical, vol. 96, no. 1-2, pp. 124-129, 2003.

[8] P.-G. Su and C.-S. Wang, "In situ synthesized composite thin films of MWCNTs/PMMA doped with $\mathrm{KOH}$ as a resistive humidity sensor," Sensors and Actuators B: Chemical, vol. 124, no. 2, pp. 303-308, 2007.

[9] Y. Li, B. Ying, L. Hong, and M. Yang, "Water-soluble polyaniline and its composite with poly(vinyl alcohol) for humidity sensing," Synthetic Metals, vol. 160, no. 5-6, pp. 455-461, 2010.

[10] A. A. A. De Queiroz, D. A. W. Soares, P. Trzesniak, and G. A. Abraham, "Resistive-type humidity sensors based on PVP-Co and PVP-I2 complexes," Journal of Polymer Science, Part B: Polymer Physics, vol. 39, no. 4, pp. 459-469, 2001.

[11] T. Fei, K. Jiang, S. Liu, and T. Zhang, "Humidity sensors based on Li-loaded nanoporous polymers," Sensors and Actuators B: Chemical, vol. 190, pp. 523-528, 2014.

[12] J. Wang and G. Song, "Mechanism analysis of $\mathrm{BaTiO}_{3}$ and polymer QAR composite humidity sensor," Thin Solid Films, vol. 515, no. 24, pp. 8776-8779, 2007.

[13] D. Patil, Y. K. Seo, Y. K. Hwang, J. S. Chang, and P. Patil, "Humidity sensitive poly (2,5-dimethoxyaniline) $/ \mathrm{WO}_{3}$ composites," Sensors and Actuators B: Chemical, vol. 132, no. 1, pp. 116124, 2008.

[14] K.-P. Yoo, L.-T. Lim, N.-K. Min, M. J. Lee, C. J. Lee, and C.-W. Park, "Novel resistive-type humidity sensor based on multiwall carbon nanotube/polyimide composite films," Sensors and Actuators B: Chemical, vol. 145, no. 1, pp. 120-125, 2010.

[15] P.-G. Su, Y.-L. Sun, and C.-C. Lin, "Novel low humidity sensor made of $\mathrm{TiO}_{2}$ nanowires/poly(2-acrylamido-2-methylpropane sulfonate) composite material film combined with quartz crystal microbalance," Talanta, vol. 69, no. 4, pp. 946-951, 2006.
[16] P.-G. Su and C.-P. Wang, "Flexible humidity sensor based on $\mathrm{TiO}_{2}$ nanoparticles-polypyrrole-poly-[3-(methacrylamino)propyl] trimethyl ammonium chloride composite materials," Sensors and Actuators B: Chemical, vol. 129, no. 2, pp. 538-543, 2008.

[17] P.-G. Su and L.-N. Huang, "Humidity sensors based on $\mathrm{TiO}_{2}$ nanoparticles/polypyrrole composite thin films," Sensors and Actuators, B: Chemical, vol. 123, no. 1, pp. 501-507, 2007.

[18] Q. Kuang, C. Lao, L. W. Zhong, Z. Xie, and L. Zheng, "Highsensitivity humidity sensor based on a single $\mathrm{SnO}_{2}$ nanowire," Journal of the American Chemical Society, vol. 129, no. 19, pp. 6070-6071, 2007.

[19] F. Hernandez-Ramirez, S. Barth, A. Tarancon et al., "Water vapor detection with individual tin oxide nanowires," Nanotechnology, vol. 18, no. 42, Article ID 424016, 2007.

[20] P.-G. Su and W.-Y. Tsai, "Humidity sensing and electrical properties of a composite material of nano-sized $\mathrm{SiO}_{2}$ and poly(2-acrylamido-2-methylpropane sulfonate)," Sensors and Actuators B: Chemical, vol. 100, no. 3, pp. 417-422, 2004.

[21] J. Wang, M.-Y. Su, J.-Q. Qi, and L.-Q. Chang, "Sensitivity and complex impedance of nanometer zirconia thick film humidity sensors," Sensors and Actuators B: Chemical, vol. 139, no. 2, pp. 418-424, 2009.

[22] Y. Li, M. J. Yang, and Y. She, "Humidity sensors using in situ synthesized sodium polystyrenesulfonate/ZnO nanocomposites," Talanta, vol. 62, no. 4, pp. 707-712, 2004.

[23] N. Horzum, D. Taşçioglu, S. Okur, and M. M. Demir, "Humidity sensing properties of $\mathrm{ZnO}$-based fibers by electrospinning," Talanta, vol. 85, no. 2, pp. 1105-1111, 2011.

[24] Y. Zhang, K. Yu, S. Ouyang et al., "Detection of humidity based on quartz crystal microbalance coated with $\mathrm{ZnO}$ nanostructure films," Physica B: Condensed Matter, vol. 368, no. 1-4, pp. 94-99, 2005.

[25] J. Xie, H. Wang, Y. Lin, Y. Zhou, and Y. Wu, "Humidity sensing properties of $\mathrm{ZnO}$ colloid crystals coated on quartz crystal microbalance by the self-assembly method," Ceramics International, vol. 39, no. 4, pp. 3621-3625, 2013.

[26] A. Erol, S. Okur, N. Yağmurcukardeş, and M. Ç. Arıkan, "Humidity-sensing properties of a $\mathrm{ZnO}$ nanowire film as measured with a QCM," Sensors and Actuators B: Chemical, vol. 152, no. 1, pp. 115-120, 2011.

[27] Q. Qi, T. Zhang, Q. J. Yu et al., "Properties of humidity sensing $\mathrm{ZnO}$ nanorods-base sensor fabricated by screen-printing," Sensors and Actuators B: Chemical, vol. 133, no. 2, pp. 638-643, 2008.

[28] J. Xu, J. Han, Y. Zhang, Y. Sun, and B. Xie, "Studies on alcohol sensing mechanism of $\mathrm{ZnO}$ based gas sensors," Sensors and Actuators B: Chemical, vol. 132, no. 1, pp. 334-339, 2008.

[29] T.-J. Hsueh, C.-L. Hsu, S.-J. Chang, and I.-C. Chen, "Laterally grown $\mathrm{ZnO}$ nanowire ethanol gas sensors," Sensors and Actuators B: Chemical, vol. 126, no. 2, pp. 473-477, 2007.

[30] Z. Yang, L.-M. Li, Q. Wan, Q.-H. Liu, and T.-H. Wang, "Highperformance ethanol sensing based on an aligned assembly of ZnO nanorods," Sensors and Actuators B: Chemical, vol. 135, no. 1, pp. 57-60, 2008.

[31] S.-J. Chang, T.-J. Hsueh, I.-C. Chen et al., "Highly sensitive $\mathrm{ZnO}$ nanowire acetone vapor sensor with Au adsorption," IEEE Transactions on Nanotechnology, vol. 7, no. 6, pp. 754-759, 2008.

[32] X. Wang, J. Zhang, and Z. Zhu, "Ammonia sensing characteristics of $\mathrm{ZnO}$ nanowires studied by quartz crystal microbalance," Applied Surface Science, vol. 252, no. 6, pp. 2404-2411, 2006. 
[33] E. Oh, H.-Y. Choi, S.-H. Jung et al., "High-performance $\mathrm{NO}_{2}$ gas sensor based on $\mathrm{ZnO}$ nanorod grown by ultrasonic irradiation," Sensors and Actuators B: Chemical, vol. 141, no. 1, pp. 239-243, 2009.

[34] T. Krishnakumar, R. Jayaprakash, N. Pinna et al., "CO gas sensing of $\mathrm{ZnO}$ nanostructures synthesized by an assisted microwave wet chemical route," Sensors and Actuators B: Chemical, vol. 143, no. 1, pp. 198-204, 2009.

[35] C. Wang, X. Chu, and M. Wu, "Detection of $\mathrm{H}_{2} \mathrm{~S}$ down to $\mathrm{ppb}$ levels at room temperature using sensors based on $\mathrm{ZnO}$ nanorods," Sensors and Actuators B: Chemical, vol. 113, no. 1, pp. 320-323, 2006

[36] O. Lupan, G. Chai, and L. Chow, "Novel hydrogen gas sensor based on single $\mathrm{ZnO}$ nanorod," Microelectronic Engineering, vol. 85, no. 11, pp. 2220-2225, 2008.

[37] U. Lange, N. V. Roznyatovskaya, and V. M. Mirsky, "Conducting polymers in chemical sensors and arrays," Analytica Chimica Acta, vol. 614, no. 1, pp. 1-26, 2008.

[38] H. Bai and G. Shi, "Gas sensors based on conducting polymers," Sensors, vol. 7, no. 3, pp. 267-307, 2007.

[39] K. Suri, S. Annapoorni, A. K. Sarkar, and R. P. Tandon, "Gas and humidity sensors based on iron oxide-polypyrrole nanocomposites," Sensors and Actuators B: Chemical, vol. 81, no. 2-3, pp. 277-282, 2002.

[40] N. Parvatikar, S. Jain, S. V. Bhoraskar, and M. V. N. Ambika Prasad, "Spectroscopic and electrical properties of polyaniline/ $\mathrm{CeO}_{2}$ composites and their application as humidity sensor," Journal of Applied Polymer Science, vol. 102, no. 6, pp. 5533-5537, 2006.

[41] H. Cankurtaran, O. Yazici, S. Dinc, and F. Karaman, "Humidity sensitive properties of electronically conductive poly(diphenylamine sulfonic acid) and its block copolymer and blends," International Journal of Electrochemical Science, vol. 8, no. 3, pp. 3265-3278, 2013.

[42] E. P. Plueddemann, Silane Coupling Agents, Plenum Press, New York, NY, USA, 2nd edition, 1991.

[43] F. Zucchi, A. Frignani, V. Grassi, G. Trabanelli, and M. DalColle, "The formation of a protective layer of 3-mercapto-propyltrimethoxy-silane on copper," Corrosion Science, vol. 49, no. 3, pp. 1570-1583, 2007.

[44] F. Hua and E. Ruckenstein, "Synthesis of a water-soluble diblock copolymer of polysulfonic diphenyl aniline and poly(ethylene oxide)," Journal of Polymer Science Part A: Polymer Chemistry, vol. 42, no. 9, pp. 2179-2191, 2004.

[45] J. Joo, D. Lee, M. Yoo, and S. Jeon, " $\mathrm{ZnO}$ nanorod-coated quartz crystals as self-cleaning thiol sensors for natural gas fuel cells," Sensors and Actuators B: Chemical, vol. 138, no. 2, pp. 485-490, 2009.

[46] P. W. Sadik, S. J. Pearton, D. P. Norton, E. Lambers, and F. Ren, "Functionalizing $\mathrm{Zn}$ - and O-terminated $\mathrm{ZnO}$ with thiols," Journal of Applied Physics, vol. 101, Article ID 104514, 2007.

[47] H. Xu, J. K. Jin, Y. Mao et al., "Synthesis of sulfur-containing polyacetylenes and fabrication of their hybrids with $\mathrm{ZnO}$ nanoparticles," Macromolecules, vol. 41, no. 11, pp. 3874-3883, 2008.

[48] M. Kikuchi and S. Shiratori, "Quartz Crystal Microbalance (QCM) sensor for $\mathrm{CH}_{3} \mathrm{SH}$ gas by using polyelectrolyte-coated sol-gel film," Sensors and Actuators B: Chemical, vol. 108, no. 1-2, pp. 564-571, 2005.

[49] K. P. Lee, A. I. Gopalan, S. H. Lee, A. Md. Showkat, and Y. C. Nho, "Synergic influence of a surfactant and ultrasonication on the preparation of soluble, conducting polydiphenylamine/ silica-nanoparticle composites," Journal of Applied Polymer Science, vol. 102, no. 4, pp. 3912-3918, 2006.

[50] A. Erol, S. Okur, B. Comba, Ö. Mermer, and M. Ç. Arikan, "Humidity sensing properties of $\mathrm{ZnO}$ nanoparticles synthesized by sol-gel process," Sensors and Actuators B: Chemical, vol. 145, no. 1, pp. 174-180, 2010.

[51] C. H. Hamann, A. Hamnett, and W. Vielstich, Electrochemistry, Wiley-VCH, Weinheim, Germany, 2nd edition, 2007.

[52] J.-H. Cho, J.-B. Yu, J.-S. Kim, S.-O. Sohn, D.-D. Lee, and J.-S. Huh, "Sensing behaviors of polypyrrole sensor under humidity condition," Sensors and Actuators B: Chemical, vol. 108, no. 1-2, pp. 389-392, 2005. 


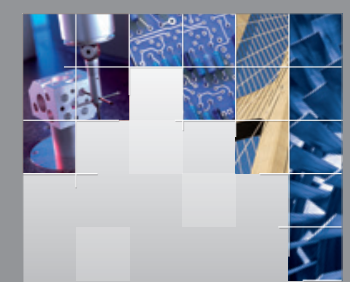

\section{Enfincering}
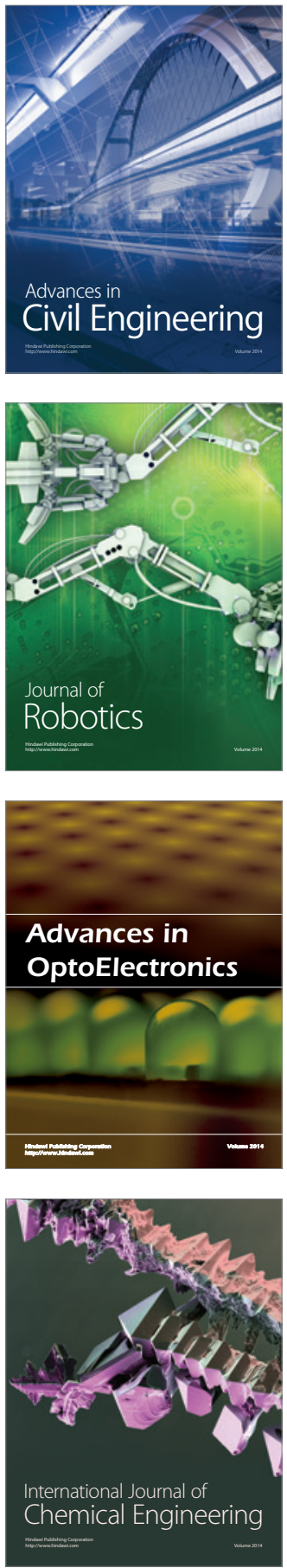

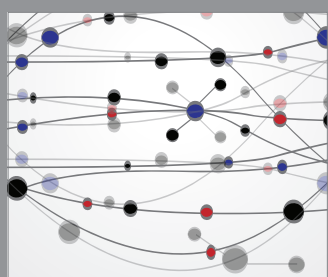

The Scientific World Journal

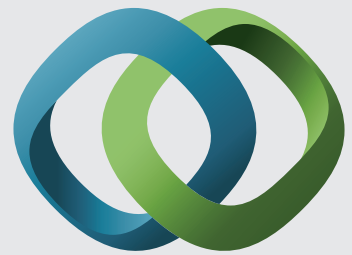

\section{Hindawi}

Submit your manuscripts at

http://www.hindawi.com
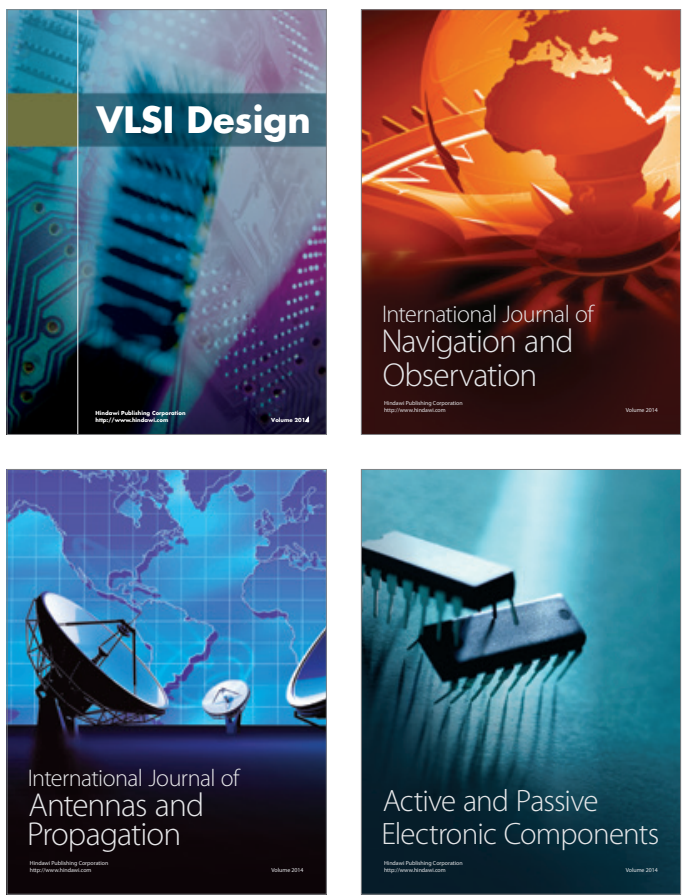
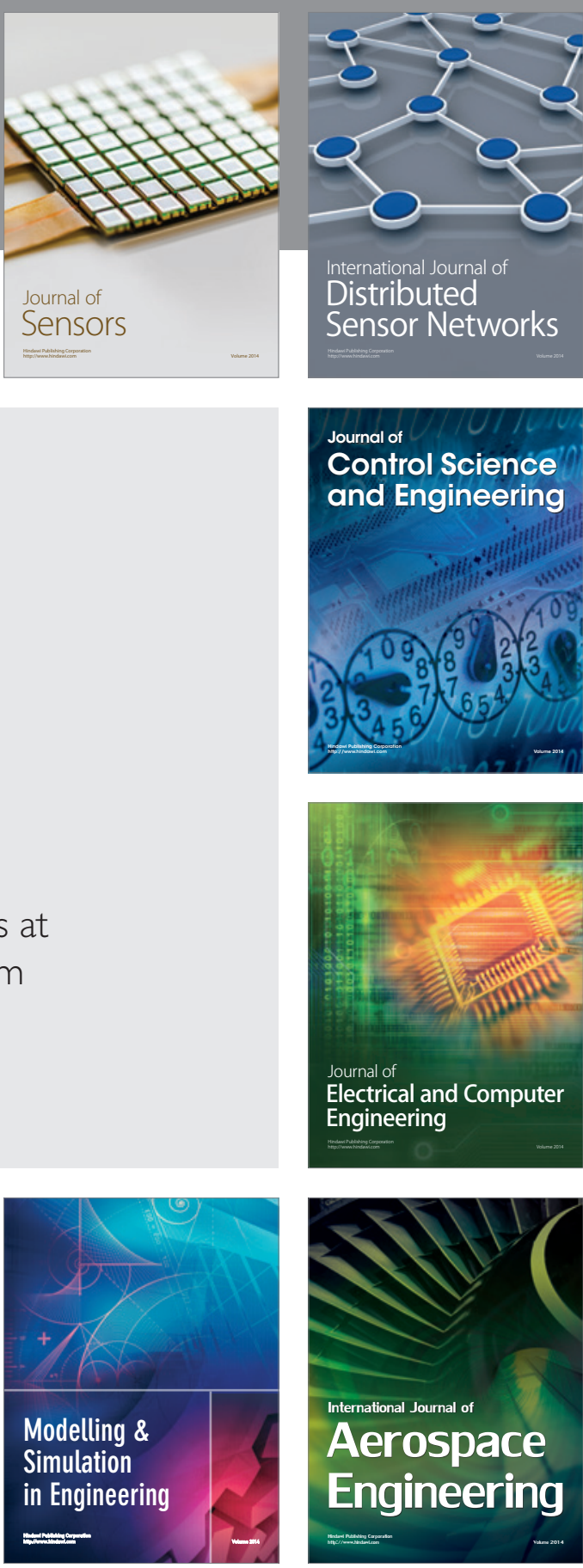

International Journal of

Distributed

Sensor Networks

Journal of

Control Science

and Engineering
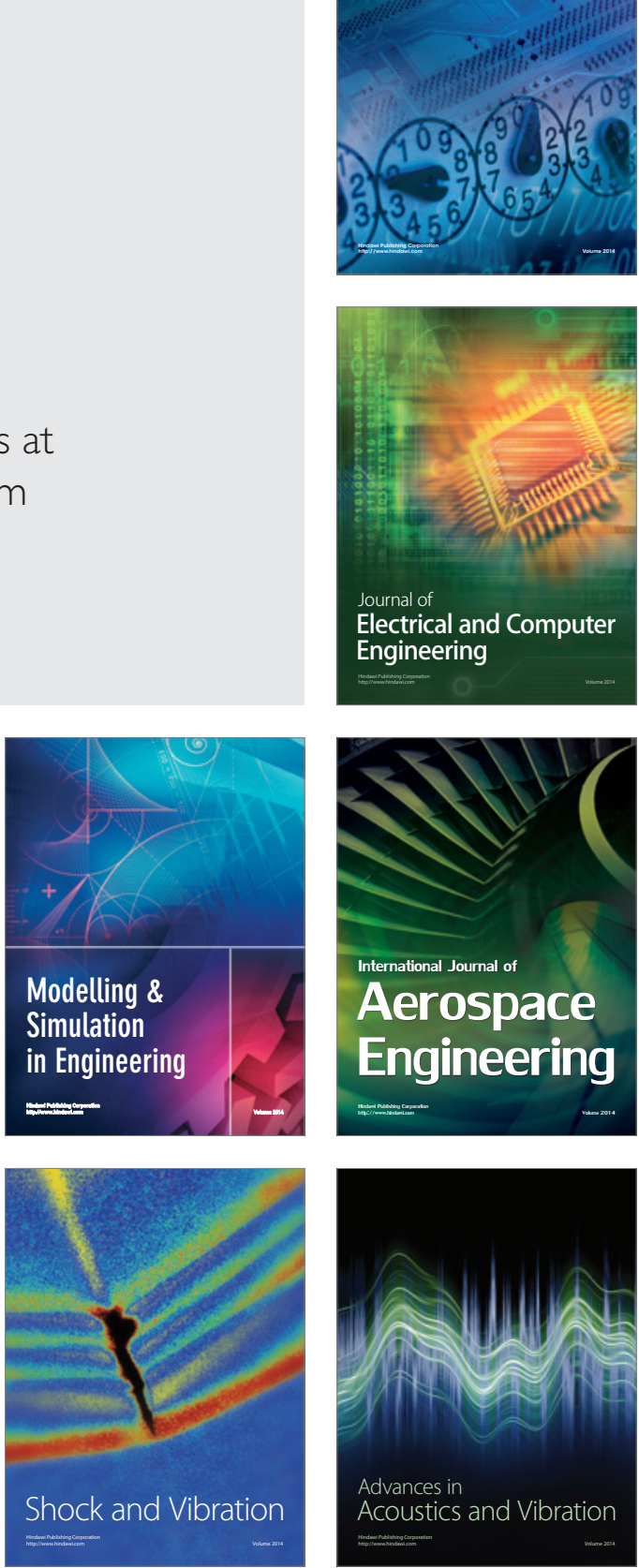